\title{
Nanoscale Chemical Structure Variations in Nano-patterned and Nano-Porous low-k Dielectrics: A Comparative Photothermal Induced Resonance and Infrared Spectroscopy Investigation
}

Qichi Hu, ${ }^{1}$ Kevin Kjoller, ${ }^{*}$ Alan Myers, ${ }^{2}$ Kanwal Jit Singh,${ }^{2}$ Sean W. King, ${ }^{3 \#}$

${ }^{1}$ Anasys Instruments Incorporated, Santa Barbara, CA, 93101, USA

${ }^{2}$ Components Research, Intel Corporation, Hillsboro, OR, 97124, USA

${ }^{3}$ Logic Technology Development, Intel Corporation, Hillsboro, OR, 97124, USA

$\underline{\text { *kevin@anasysinstruments.com, }}, \stackrel{{ }^{*} \text { sean.king@intel.com }}{ }$

ABSTRACT. The recent development of the photothermal induced resonance (PTIR) technique has enabled atomic force microscope based infrared (AFM-IR) spectroscopy and imaging to be achieved at the nanometer scale. However, a direct correspondance between PTIR/AFM-IR and more traditional Fourier transform IR (FTIR) spectroscopy has been prohibited for nanometer scale features due to Rayleigh diffraction constraints that limit the latter to few micron spatial resolution. In this regard, we have overcome this challenge by fabricating $1 \mathrm{~cm}^{2}$ arrays of $90 \mathrm{~nm}$ wide fins in a nano-porous low dielectric constant (i.e. low-k) amorphous hybrid inorganicorganic silicate material using standard nano-electronic fabrication techniques. With these structures, we demonstrate both a general correspondance between AFM-IR, FTIR, and Germanium attenuated total reflection (GATR) IR spectroscopy, as well as differences in the sensitivities that these techniques exhibit to the nanoscale variations in chemical structure induced in the low-k dielectric by the nanopatterning method. To further illustrate the sensitivity of AFM-IR to changes in chemical structure with nanometer resolution, the nanopatterned low-k 
dielectric was exposed to additional oxidizing plasma ash cleans post patterning. Focusing on the Si- $\mathrm{CH}_{3}$ deformation band at $\sim 1275 \mathrm{~cm}^{-1}$, both the AFM-IR, FTIR and GATR measurements show a clear reduction in the concentration of terminal methyl groups in the low-k dielectric as the oxidation potential of the plasma ash clean increased. These results further establish the power of AFM-IR to perform nanoscale IR spectroscopy and demonstrates a stronger correspondance between AFM-IR and well-known micron scale IR techniques such as FTIR and GATR.

KEYWORDS: Photothermal induced resonance, atomic force microscopy, Fourier transform, infrared spectroscopy, Germanium attenuated total reflection, dielectric, organo-silicate. 


\section{Introduction}

As a result of the relentless pursuit of Moore's law [1], the microelectronics industry has in the recent decade quietly entered deep into the realm of the nanometer with single digit nanometer technologies now currently in early stages of research and development [2,3]. These achievements have been driven not only by advances in new materials and nanofabrication technologies, but also by metrologies capable of imaging and distinguishing features and properties with nanometer or sub-nanometer resolution [4]. In this regard, optical and x-ray scattering techniques $[5,6]$ and electron beam and scanned probed microscopies $[7,8]$ have been at the forefront for measuring critical dimensions, atomic structure, elemental composition and material properties $[9,10]$. However, attempts to extend popular chemical bonding / molecular structure identification techniques such as infrared (IR) spectroscopy from the micron into the nanometer range have been prohibited by diffraction limitations defined by the Rayleigh equation $[11,12]$.

Recently, the spatial resolution constraints of traditional far-field IR spectroscopies have been overcome by the development of the photothermal induced resonance (PTIR) technique $[13,14]$. PTIR combines the lateral resolution of an atomic force microscope (AFM) with the chemical specificity of IR spectroscopy [15-17] and is more commonly referred to as AFM-IR [18]. In many cases, a strong and direct correspondence has been demonstrated between AFM-IR and far-field IR spectra of bulk and thin film materials [19-23]. However, only a few combined AFM-IR and far-field IR investigations of micron scale materials have been reported and show only a general correspondence $[24,25]$. In this article, we demonstrate a direct correspondance at the nanometer scale between AFM-IR and far-field IR spectroscopies such as Fourier transform 
(FTIR) and germanium attenuated total reflection (GATR) using $1 \mathrm{~cm}^{2}$ arrays of $90 \mathrm{~nm}$ wide fins patterned into a nano-porous low dielectric constant (low- $k$ ) hybrid inorganic-organic silicate film [26]. We further demonstrate the ability of AFM-IR to observe nanoscale changes in the chemical structure of the low-k dielectric fins induced by the nanopatterning process and by exposure to post patterning oxidizing plasma ash cleans.

Low-k dielectric materials are a particularly important research material due to the nanoelectronic industry's need to reduce parasitic capacitive signal delays and power loss in transistor and metal interconnect structures $[27,28]$. Despite this motivation, the adoption of low$\mathrm{k}$ dielectrics with increasingly reduced values of dielectric permittivity and corresponding increased nano-porosity has been extremely problematic due to the greatly reduced thermal, electrical, and mechanical properties exhibited by these materials $[29,30]$. The hybrid inorganicorganic structure and coupled intrinsic nano-porosity of low-k silicate dielectrics also makes these materials extremely susceptible to further reductions in properties during nanofabrication via removal of the organic component by plasma etch and cleans processes and attack of the inorganic silicate component by aqueous chemical cleaning solutions [31-33]. The chemical modification and diminished properties can lead to loss of patterning dimensional control [34,35], catastrophic mechanical failure during fabrication and packaging [36-39], and severely degraded electrical reliability in the final product $[40,41]$.

Fortunately, the chemical structure / bonding of low-k dielectrics is ideally suited for characterization by IR spectroscopy due to the strong IR activity of both the organic component (through various $\mathrm{C}-\mathrm{H}$ stretching and deformation bands) and the inorganic component (through the Si-O and Si-H stretching bands) [42]. Numerous FTIR, GATR and multiple internal reflection IR (MIRIR) spectroscopy investigations of the chemical modification of low-k 
dielectrics by various nanofabrication processes have been performed on blanket films [43-49] and in some cases large periodic arrays of $\mu \mathrm{m}-\mathrm{nm}$ wide patterned features [26,50-52]. These studies have established general trends and correlations between process chemistries and the low-k dielectric chemical bond structure to the susceptibility of process induced chemical modification. However, the variation in low-k dielectric chemical modification directly within minimum size features and feature to feature has yet to be characterized due to the limited spatial resolution of the FTIR, GATR, and MIRIR techniques. Large arrays of uniform structures are also of limited utility for investigating chemical modification in actual integrated products where micron-macro scale periodic arrays of nanometer scale features can be incompatible with typical product designs.

In this regard, AFM-IR is ideally suited for characterizing and performing failure analysis of nano-patterned low-k dielectric and integrated metal interconnect structures due to the ability to both detect and probe with high spatial resolution the chemical bonds of interest. In a previous AFM-IR study, a direct correspondence between AFM-IR and FTIR was demonstrated for both an unpatterned micron thick low-k dielectric film and a patterned low-k dielectric metal interconnect structure with micron scale features [53]. However for nanometer scale features, the reduced IR absorption cross section and comparatively low coefficient of thermal expansion (CTE) for low-k dielectrics [54,55] presents unique challenges to the PTIR technique due primarily to the IR absorbance being detected as a thermal expansion of the test specimen [56]. Therefore, we additionally demonstrate in this article that PTIR/AFM-IR has the capability to address some of the challenges associated with nano-structured low-k dielectric/metal interconnect structures as well as characterize similar nanoscale structures composed of low CTE materials. 


\section{Materials and methods}

\subsection{FTIR and GATR}

Transmission Fourier transform infrared (FTIR) spectroscopy was performed using a Thermo Scientific Nicolet 6700 FTIR spectrometer and deuterated L-alanine doped triglycine sulfate (DLaTGS) detector. The normal incidence IR transmission spectra of the low-k dielectric on $\mathrm{Si}$ substrate samples were collected using an open beam background. All spectra were acquired from $400-7000 \mathrm{~cm}^{-1}$ with $4 \mathrm{~cm}^{-1}$ resolution and signal averaged over 128 scans. The spectrum of the Si substrate was obtained using the same acquisition settings after manually scraping off the low-k film. This spectrum was utilized for removing the Si substrate absorption from the low-k/Si spectrum as well as correcting for optical interference effects common in thin film on thick substrate transmission measurements. The latter corrections used rigorous methods that account for the full wave nature of light and have been previously described in detail [5759].

The germanium attenuated total reflectance (GATR) IR measurements were performed using a Harrick Ge ATR attachment mounted on the Thermo spectrometer and utilized a liquid nitrogen cooled mercury-cadmium-telluride (MCT) detector. The GATR spectra were collected from $650-4000 \mathrm{~cm}^{-1}$ with $4 \mathrm{~cm}^{-1}$ resolution and averaged over 128 scans. The GATR spectra are presented without additional processing.

\subsection{AFM-IR}

The photothermal induced resonance measurements were performed using an Anasys Instruments NanoIR2 [53]. IR spectra were collected by directly exposing the surface of the 
various low-k dielectric fin arrays to a broadly tunable nanosecond optical parameter oscillator (OPO) IR laser beam focussed onto the sample at a polar angle of $20^{\circ}$ and an approach angle of $60^{\circ}$. This orientation allowed both the IR laser and the AFM probe tip / detector to co-localize above the sample simultaneously. A contact mode Arrow AFM probe with a force constant of $0.07-0.4 \mathrm{~N} / \mathrm{m}$ (NanoandMore, Switzerland) was utilized in these measurements. The OPO IR source was operated with a typical pulse length of $10 \mathrm{~ns}$ and $1 \mathrm{kHz}$ repetition rate. All experimental data were collected in contact mode using Analysis Studio software (Version 3.9, Anasys Instruments, Santa Barbara, CA). IR spectra were collected from $900-1400 \mathrm{~cm}^{-1}$ at an average power of approximately one milliwatt and $4 \mathrm{~cm}^{-1}$ resolution. Due to the reduced thickness of the patterned low-k dielectric in this study, increased (2X) spectral averaging was utilized to achieve a comparable signal to noise $(\mathrm{S} / \mathrm{N})$ ratio as in a previous investigation of a thicker (10X) low-k dielectric material [53]. The cantilever oscillation amplitude was measured at the cantilever contact resonance centered around $780 \mathrm{kHz}$. This mode was selected to eliminate any ambient thermal effects at the fundamental cantilever mode and due to the high $\mathrm{S} / \mathrm{N}$ ratio at this mode [51].

\subsection{Low-k fin nanofabrication}

The nano-porous low-k dielectrics were deposited on $300 \mathrm{~mm}$ diameter Si (001) substrates on which an $8 \mathrm{~nm}$ dense a-SiOC:H etch stop layer had been previously coated. The hybrid inorganic-organic silicate low-k dielectric was deposited by plasma enhanced chemical vapor deposition using both alkoxysilane and organic pore building precursors at temperatures on the order of $250 \pm 25{ }^{\circ} \mathrm{C}$ as previously described $[58,59]$. Post deposition, the organic porogen was removed using a UV cure at temperatures on the order of $400 \pm 10{ }^{\circ} \mathrm{C}$ resulting in a $120 \mathrm{~nm}$ 
thick, $\sim 33 \%$ porous film with a dielectric constant of 2.3 [58,59]. After curing, a $50 \mathrm{~nm}$ thick TiN hardmask (HM) was deposited on top of the low-k dielectric via standard physical vapor deposition methods. Nanoscale trenches were formed in the TiN HM and then the low-k dielectric via standard lithographic and plasma etching procedures. Briefly, standard $193 \mathrm{~nm}$ immersion lithography was utilized to pattern $\sim 90 \mathrm{~nm}$ wide photoresist lines with minimum pitch values of 180, 270, and $630 \mathrm{~nm}$. A standard TiN plasma etch process was then utilized to selectively transfer the resulting pattern into the TiN mask. The photoresist grating was selectively removed using standard wet chemical and ash procedures, and the hard mask pattern was then transferred into the dielectric using a second plasma etch. The height of the formed dielectric fins (depth of the hanging trench) was controlled by the length of the low-k plasma etch. The width of the remaining dielectric fin was fixed at $90 \mathrm{~nm}$ for all the pitches. To facilitate subsequent T-FTIR, GATR, and AFM-IR measurements, the TiN HM was selectively removed using a standard TiN wet chemical etch.

After the plasma etch and TiN HM removal, additional plasma etched samples were exposed to a series of different plasma ash cleans used for removal of both remaining photoresist and plasma etch produced polymeric residues. A standard $300 \mathrm{~mm}$ plasma ashing tool was utilized and the working gas for the various plasma ash cleans consisted of the following gas combinations: $\mathrm{H}_{2}-\mathrm{He}, \mathrm{Ar}-\mathrm{N}_{2}, \mathrm{He}-\mathrm{O}_{2}$, and $\mathrm{N}_{2}-\mathrm{O}_{2}$. For consistency, the plasma clean times for the various plasma ashes were the same. 


\section{Results and discussion}

Figure 1 presents schematic illustrations and cross section scanning electron microscope (XSEM) images of the nano-patterned, nano-porous hybrid inorganic-organic silicate low-k dielectric structures investigated in this study. The samples consisted of a nominally $120 \mathrm{~nm}$ thick nano-porous $(33 \%)$ low-k dielectric film $(\mathrm{k}=2.3)$ in which hanging trenches were plasma etched into the film to a depth of $\sim 100 \mathrm{~nm}$ using nanofabrication techniques that have been previously described in detail [26,37]. In a typical low-k/metal interconnect structure, these trenches would be filled with a metal such as $\mathrm{Cu}$ to form interconnect wiring, and the remaining low-k dielectric fins would serve as electrical isolation for neighboring wires [27]. In this study, we focus only on chemical modification of the nano-porous low-k dielectric induced by both the plasma etching process and subsequent plasma ash cleans utilized to remove photoresist and plasma etch residues prior to filling the etched trenches with metal. As shown in Fig. 1, three 1 $\mathrm{cm}^{2}$ arrays of $90 \mathrm{~nm}$ wide low-k dielectric fins were prepared for this investigation with pitches (fin + trench width) of 180, 270 and $630 \mathrm{~nm}$. Additional details regarding the properties of the nano-porous low-k dielectric utilized in this study are summarized in the supplementary material.

As the silicon substrate used to fabricate the low-k dielectric fin structures was highly IR transparent, it was possible to perform transmission FTIR (T-FTIR) spectroscopy measurements on the low-k dielectric in each $1 \mathrm{~cm}^{2}$ array. Figure 2 presents different portions of the T-FTIR spectra collected from both the unpatterned nano-porous low-k dielectric (i.e. blanket film) and the patterned nano-porous low-k dielectric arrays with varying pitch. Fig. 2 a focusses on the Si$\mathrm{O}$ asymmetric network stretching mode $\left(\right.$ at $\left.\sim 1050 \mathrm{~cm}^{-1}\right)$ and the symmetric $\mathrm{Si}-\mathrm{CH}_{3}$ deformation band (at $\sim 1275 \mathrm{~cm}^{-1}$ ) that represent the inorganic and organic components of the low-k dielectric 
material, respectively [42]. To more clearly illustrate and compare differences, the peak Si-O stretching mode absorbance in each spectrum has been normalized to have the same nominal value. This clearly reveals that the absorbance for the $\mathrm{Si}-\mathrm{CH}_{3}$ deformation band from the patterned low-k dielectric decreases as the pitch of the $90 \mathrm{~nm}$ wide fin array is increased. Similarly, the Si-O "cage" stretching mode at $\sim 1150 \mathrm{~cm}^{-1}$ was also observed to decrease in absorbance as pitch width increased. This suggests the "cage" structure in low-k dielectrics is related to or created by the presence of terminal $\mathrm{CH}_{3}$ groups in the network.

A decrease in absorbance for both the $\mathrm{Si}-\mathrm{O}$ and $\mathrm{Si}_{-}-\mathrm{CH}_{3}$ bands with increasing pitch should be expected as the amount of low-k material in the IR transmission path decreases as the pitch width increases. However, the absorbance of the $\mathrm{Si}-\mathrm{O}$ and $\mathrm{Si}-\mathrm{CH}_{3}$ bands relative to one another should remain constant as a function of pitch if everything else remains the same. In this case, the decrease in absorbance for the $\mathrm{Si}_{-} \mathrm{CH}_{3}$ band with pitch could be the result of two different things. The first could be related to the dense $8 \mathrm{~nm}$ a-SiOC:H layer present between the nano-porous low-k dielectric and the $\mathrm{Si}(001)$ substrate inserted for adhesion and potential etch stopping purposes (see Fig. 1). As shown previously [60,62], the dense a-SiOC:H layer does exhibit strong absorption at $1050 \mathrm{~cm}^{-1}$ but comparitively little absorbance at $1275 \mathrm{~cm}^{-1}$. Thus, the T-FTIR spectra in Fig. 2a could increasingly represent the absorption spectrum of the dense aSiOC:H layer as pitch increases. The second possible explanation for the reduced absorbance of the $\mathrm{Si}-\mathrm{CH}_{3}$ band with increasing pitch is that $\mathrm{CH}_{3}$ groups have been preferentially removed by the plasma etching process from the $\sim 20 \mathrm{~nm}$ of nano-porous low-k dielectric remaining in the bottom of the trench and from the sidewall surfaces of the fin (see Fig. 2c). It is possible that both effects are in play. However, the latter effect seems more probable due to the 2-3X greater thickness of the remaining nano-porous low-k layer versus the dense a-SiOC:H adhesion layer. 
Also, additional absorption bands centered at $800 \mathrm{~cm}^{-1}$ characteristic of Si-C bonds in the dense a-SiOC:H layer were not observed.

Fig. $2 \mathrm{~b}$ presents the same FTIR spectra illustrated in Fig. 2a but instead focusses on the portion containing the $\mathrm{C}-\mathrm{H}$ and $\mathrm{O}-\mathrm{H}$ stretching bands at $2800-3000 \mathrm{~cm}^{-1}$ and $3200-3600 \mathrm{~cm}^{-1}$, respectively. These two bands show dissimilar behavior relative to that observed for the Si-O and $\mathrm{Si}_{-} \mathrm{CH}_{3}$ bands in Fig. 2. Specifically, both the $\mathrm{C}-\mathrm{H}$ and $\mathrm{O}-\mathrm{H}$ bands for the patterned nano-porous low-k dielectric were observed to increase substantially relative to the unpatterned nano-porous low-k dielectric. For the unpatterned nano-porous low-k dielectric, the $\mathrm{O}-\mathrm{H}$ band is undetected and the C-H absorption band shows a prominent peak at $2970 \mathrm{~cm}^{-1}$ and a weaker peak at 2920 $\mathrm{cm}^{-1}$ that are, respectively, attributed to the asymmetric and symmetric $\mathrm{C}-\mathrm{H}_{3}$ stretching modes for terminal methyl $\left(\mathrm{Si}_{-} \mathrm{CH}_{3}\right)$ groups [42]. For the patterned nano-porous low-k dielectrics, strong O-H absorption was observed and two additional peaks in the $\mathrm{C}-\mathrm{H}$ band appeared at 2860 and $2930 \mathrm{~cm}^{-1}$ that are attributed to the symmetric and asymmetric stretching modes of methylene (C-H2) groups [42].

The appearance of $\mathrm{OH}$ in low-k dielectrics post patterning is generally attributed to the removal of terminal $\mathrm{CH}_{3}$ groups during plasma etching or cleaning processes and the termination of the resulting silicon dangling bonds by $\mathrm{OH}$ groups on exposure to air/moisture [43,46,49]. This latter observation is consistent with the previously discussed decrease in the $\mathrm{Si}_{-} \mathrm{CH}_{3}$ deformation band with pitch shown in Fig. 2a, as well as the decrease in absorbance with pitch for the $\mathrm{C}-\mathrm{H}_{3}$ stretching mode at $2970 \mathrm{~cm}^{-1}$ observed in Fig. $2 \mathrm{~b}$. In fact, the increase in $\mathrm{O}-\mathrm{H}$ absorbance roughly correlates with the decrease in the $\mathrm{Si}-\mathrm{CH}_{3}$ and $\mathrm{C}-\mathrm{H}_{3}$ bands.

The appearance of $\mathrm{C}-\mathrm{H}_{2}$ groups is attributed to the presence of plasma polymerized organic polymer residues formed on the low-k dielectric surface during the patterning and 
plasma etching process (see Fig. 2c). The formation / deposition of such polymeric residues during dielectric plasma etching processes is commonly observed and attributed to both the etching and redeposition of the organic photoresists used for pattern definition and the use of highly polymerizing plasma etch gas chemistries [48,51]. Comparing the $\mathrm{C}-\mathrm{H}$ spectra for just the patterned low-k samples, the absorbance for both the $\mathrm{C}-\mathrm{H}_{2}$ and $\mathrm{C}-\mathrm{H}_{3}$ modes decrease with increasing pitch. For the $\mathrm{C}-\mathrm{H}_{3}$ stretch, this is consistent with similar observations for the $\mathrm{Si}-\mathrm{CH}_{3}$ deformation band. For the $\mathrm{C}-\mathrm{H}_{2}$ stretch, this is consistent with both the etched surface area and photoresist surface coverage decreasing with increasing pitch.

GATR IR measurements performed on the same samples investigated in Fig. 2 showed similar spectra and general trends (see supplemental material for comparision spectra). However, some subtle differences were observed. Specifically, the $\mathrm{Si}-\mathrm{CH}_{3} / \mathrm{Si}-\mathrm{O}$ ratio for the GATR spectra showed a much weaker dependence on pitch and only agreed with the values from T-FTIR at $630 \mathrm{~nm}$ pitch (see Figure 3). This may be related to differences in optical coupling efficiency as well as differences in the IR transmission path for T-FTIR versus GATR [11,12]. For the T-FTIR measurements, the IR beam is normal to the plane of the patterned low-k dielectric and is insensitive to the orientation of the patterned lines within the plane (see Figure 4a). However in GATR, the IR beam traverses in the same plane as the low-k dielectric and the patterned lines can be oriented either in parallel or perpendicular to the IR source (see Figs. $4 \mathrm{~b}$ and $4 \mathrm{c}$ ). For the GATR spectra illustrated in the supplemental material, the low-k fins were oriented parallel to the direction of the IR evanescent wave (i.e. GATR-parallel). We postulate that for this geometry, reduced IR coupling occurs in the remaining portion of the low-k dielectric in the bottom of the etched trench and that most of the GATR-parallel signal therefore comes from the dielectric fins. However for T-FTIR, the IR evanescent wave transmits more through both the 
bulk and surfaces of the fins as well as the bottom of the etched trenches. Therefore, T-FTIR spectra of the patterned low-k structures represents a composite of absorption by both the low-k dielectric fins and the remaining low-k dielectric in the bottom of the etched trench. This would partially explain the relatively weak dependence of the $\mathrm{Si}-\mathrm{CH}_{3} / \mathrm{Si}-\mathrm{O}$ ratio on pitch for the GATRparallel spectra and the more pronounced dependence observed using T-FTIR.

As for T-FTIR and GATR-parallel agreeing for $\mathrm{Si}-\mathrm{CH}_{3} / \mathrm{Si}-\mathrm{O}$ ratio only at $630 \mathrm{~nm}$ pitch, this may be serendipitous and/or the result of different effects producing similar results. As described above, a large portion of the low-k volume probed by T-FTIR in the $630 \mathrm{~nm}$ pitch structure is from the bottom of the plasma etched hanging trenches. In contrast, GATR-parallel probes mostly the low-k fin whose top surface was protected from the plasma etch by a TiN hardmask (HM) deposited before photoresist coating and then subsequently removed after the plasma etch to enable T-FTIR, GATR, and AFM-IR measurements. Thus, the reduced Si$\mathrm{CH}_{3} / \mathrm{Si}$-O ratio in GATR-parallel can not be purely related to the plasma etching process. This is consistent with the comparatively lower absorbance from the plasma etch residue related $\mathrm{C}-\mathrm{H}_{2}$ strech detected by GATR-parallel relative to T-FTIR (see Fig. 2 and supplemental material). However, prior to TiN deposition, an in-situ plasma pre-clean was utilized to improve adhesion between the TiN HM and the low-k dielectric. As we will show later, such plasma cleans are also efficient at removing terminal $\mathrm{CH}_{3}$ groups. Therefore, the in-situ plasma pre-clean and associated $\mathrm{N}_{2}{ }^{+}$bombardment during the TiN physical vapor deposition may have depleted the top surface of the low-k fin of terminal $\mathrm{CH}_{3}$ groups to a similar degree as the plasma etch depleted the fin sidewalls and the hanging trench bottoms. As any TiN $\mathrm{HM}$ related $\mathrm{CH}_{3}$ loss would have occurred prior to patterning and plasma etching, this could also explain the weak $\mathrm{Si}_{-} \mathrm{CH}_{3} / \mathrm{Si}-\mathrm{O}$ pitch dependence observed by GATR-parallel. 
Figure 5 presents AFM-IR spectra of the $\mathrm{Si}-\mathrm{O}$ and $\mathrm{Si}-\mathrm{CH}_{3}$ bands from the same patterned low-k dielectrics presented in Fig. 2 where the AFM-IR tip/detector was positioned directly on top of the low-k fin (see Fig. 4d). The AFM-IR spectra exhibited some similarities and differences relative to the previously discussed T-FTIR and GATR-parallel spectra. Compared to T-FTIR, the lineshape of the Si-O band in AFM-IR is almost identical and the $\mathrm{Si}_{-} \mathrm{CH}_{3}$ band in AFM-IR also exhibits a general decrease with increasing pitch. However, Fig. 3 shows that the $\mathrm{Si}-\mathrm{CH}_{3} / \mathrm{Si}-\mathrm{O}$ ratio for the 180 and $270 \mathrm{~nm}$ PTIR spectra are roughly the same before clearly decreasing at $630 \mathrm{~nm}$ in contrast to T-FTIR. Also in contrast to both T-FTIR and GATR-parallel, the peak absorbance for the $\mathrm{Si}-\mathrm{CH}_{3}$ band in AFM-IR is at $\sim 1260-1265 \mathrm{~cm}^{-1}$ for 180 and 270 $\mathrm{nm}$ pitch and then switches to $1270 \mathrm{~cm}^{-1}$ for $630 \mathrm{~nm}$ pitch. In both T-FTIR and GATR, peak absorbance for the $\mathrm{Si}-\mathrm{CH}_{3}$ band is at $1270-1275 \mathrm{~cm}^{-1}$ with only a small shoulder at $1265 \mathrm{~cm}^{-1}$ being observed. We do note that in a previous AFM-IR investigation of unpatterned / blanket low-k dielectric films [53], peak $\mathrm{Si}_{-} \mathrm{CH}_{3}$ absorbance was at $1275 \mathrm{~cm}^{-1}$ similar to T-FTIR and GATR. This indicates that the difference in wavenumber position detected by AFM-IR for the $\mathrm{Si}-\mathrm{CH}_{3}$ band in Fig. 5 is due to the patterning process and not an artifact of the technique.

To allow a better visual comparison of the T-FTIR, GATR, and AFM-IR spectra for the $\mathrm{Si}-\mathrm{O}$ and $\mathrm{Si}-\mathrm{CH}_{3}$ bands, we plot in Figure 6 the IR spectra obtained from each technique for the $180 \mathrm{~nm}$ pitch sample. Included in Fig. 6 are GATR spectra obtained with the low-k fins oriented both parallel and perpendicular to the IR source. Comparison of the various spectra quickly reveals that while the Si-O band in all cases appears similar, the $\mathrm{Si}-\mathrm{CH}_{3}$ band exhibits significant differences. Specifically, peak absorbance for the $\mathrm{Si}_{-} \mathrm{CH}_{3}$ band in T-FTIR and GATR (with the fins oriented both parallel and perpendicular) is at $\sim 1275 \mathrm{~cm}^{-1}$ with a shoulder at $1265 \mathrm{~cm}^{-1}$ that increases in intensity from T-FTIR to GATR-parallel to GATR-perpendicular. In contrast, peak 
intensity for the $\mathrm{Si}-\mathrm{CH}_{3}$ band in AFM-IR is at $1265 \mathrm{~cm}^{-1}$ with a shoulder at $1275 \mathrm{~cm}^{-1}$. The GATR-perpendicular spectra is actually somewhat intermediate between GATR-parallel and AFM-IR with the peak absorbance at $1265 \mathrm{~cm}^{-1}$ approaching that at $1275 \mathrm{~cm}^{-1}$.

Absorbance at $1270 \mathrm{~cm}^{-1}$ has been previously attributed to $\left(\mathrm{CH}_{3}\right) \mathrm{SiO}_{3}$ groups while absorption at $1260 \mathrm{~cm}^{-1}$ and $1250 \mathrm{~cm}^{-1}$ has been attributed to $\left(\mathrm{CH}_{3}\right)_{2} \mathrm{SiO}_{2}$ and $\left(\mathrm{CH}_{3}\right)_{3} \mathrm{SiO}$ groups, respectively [42]. Since the AFM-IR signal / sensitivity decreases away from the top surface of the low-k fin due to attenuation of the IR evanescent wave (see Fig. 4d), this suggests the possibility for preferential (or enhanced) removal of $\mathrm{CH}_{3}$ from $\mathrm{CH}_{3} \mathrm{SiO}_{3}$ versus $\left(\mathrm{CH}_{3}\right)_{2} \mathrm{SiO}_{2}$ groups in the top of the low-k fin by the patterning process (either via the TiN plasma pre-clean or plasma etch). As will be discussed next, this is supported by further consideration of the geometry of the various measurements, the portion of the patterned low-k probed by each technique, and pattern dependent gradients in the chemical structure of the low-k dielectric.

For T-FTIR, the spectra represent a composite of the IR absorption by the unperturbed low-k dielectric in the fins and the bottom of the etched trenches as well as any chemically modified surface layers present on the top and sidewall of the fins and the trench bottoms. In contrast, the GATR-parallel spectra represent mostly absorption by the low-k fin due to the airgap between the Ge ATR element and the bottom of the low-k hanging trenches causing reduced coupling. For GATR-perpendicular, however, the spectra exhibit enhanced sensitivity to both the top of the low-k fin (due to the IR coupling path being periodically broken) and the low-k fin sidewall surfaces (due to the IR path being forced to transmit directly through the fin sidewalls by geometry) (see Fig. 4c). Similarly, AFM-IR spectra are representative only of the low-k fin due to the AFM tip being located directly on the fin top surface and therefore being capable of only detecting IR absorption by the fin via photothermal induced expansion of the fin (see Fig. 
4d). Likewise, AFM-IR may be similarly more sensitive to chemical modification of the top surface of the low-k fin due to the intensity of the IR evanescent wave decreasing exponentially from the fin surface into the bulk.

The above discussion concerning the differences in portions of the patterned low-k structures sampled by the various techniques and the differences in their sensitivities is consistent with the model presented in Fig. $2 \mathrm{c}$ of the surfaces of the patterned low-k dielectric being chemically modified (or "damaged") and the spectra presented in Fig. 6. Specifically, the increased absorption at $1265 \mathrm{~cm}^{-1}$ for the $\mathrm{Si}-\left(\mathrm{CH}_{3}\right)_{2}$ mode relative to the $\mathrm{Si}-\mathrm{CH}_{3}$ mode at 1275 $\mathrm{cm}^{-1}$ in moving from T-FTIR to GATR-parallel to GATR-perpendicular to AFM-IR spectra, strongly points to the presence of a chemically modified layer on the top surface of the low-k fins that is selectively or preferentially depleted of mono- $\mathrm{CH}_{3}$ groups by the TiN HM pre-clean. The fact that similar behavior is observed by all techniques as pitch increases to $630 \mathrm{~nm}$ suggests that the plasma etch removes mono $\mathrm{CH}_{3}$ groups from the fin sidewalls and hanging trench bottoms in a similar fashion.

The above rationalization for the differences in $\mathrm{Si}_{-} \mathrm{CH}_{3}$ wavenumber position detected by AFM-IR, however, does not explain the observed AFM-IR Si-CH3 pitch dependence shown in Figs. 3 and 5. To explain the observed AFM-IR Si-CH3 pitch dependence, we hypothesize that at 180 and $270 \mathrm{~nm}$ pitch most of the mono $\mathrm{CH}_{3}$ loss from the low-k fin occurs due to the TiN HM pre-clean. Since the TiN HM deposition is performed prior to pattern definition, this would be consistent with the relatively small change in $\mathrm{Si}-\mathrm{CH}_{3} / \mathrm{Si}-\mathrm{O}$ ratio from 180 to $270 \mathrm{~nm}$ pitch. It would also be consistent with a higher amount of polymer residue formed on the fin sidewalls by the plasma etch as observed by the increased $\mathrm{C}-\mathrm{H}_{2}$ absorbance in T-FTIR for 180 and $270 \mathrm{~nm}$ pitch (see Fig. 2). At $630 \mathrm{~nm}$ pitch, we further hypothesize that additional loss of $\mathrm{CH}_{3}$ occurs 
from the fin sidewalls due to reduced formation of sidewall polymer. This would be consistent with the reduced level of $\mathrm{C}-\mathrm{H}_{2}$ absorbance in the T-FTIR measurements at $630 \mathrm{~nm}$. The $630 \mathrm{~nm}$ pitch AFM-IR spectra would thus potentially indicate nearly complete removal of $\mathrm{CH}_{3}$ groups within the AFM-IR sampling depth with only a small amount of mono $\mathrm{CH}_{3}$ being detected in unpreturbed/bulk low-k deep within the low-k fin and beyond the fin interaction volume with the TiN HM pre-clean and plasma etch.

Additional insight concerning interpretation of the AFM-IR spectra in Fig. 5 could be gained by collecting AFM-IR spectra of the C-H stretch from the low-k fin and performing additional AFM-IR measurements on the nano-porous low-k dielectric remaining in the bottom of the plasma etched hanging trenches. Unfortunately, AFM-IR spectra with sufficient $\mathrm{S} / \mathrm{N}$ ratio were not obtained in both cases. This is due to AFM-IR thickness limitations and reduced sensitivity for the C-H stretch in low-k materials. As we have previously shown [53], the C-H stretch is undetectable at thicknesses $<250 \mathrm{~nm}$ in low-k dielectric materials and for the thickness of the low-k dielectric in the hanging trench bottom $(\sim 20 \mathrm{~nm})$, the Si-O stretch was equally undetectable. For the latter, we note that for polymeric samples (with higher values of CTE) 50 $\mathrm{nm}$ is the thinnest film for which AFM-IR spectra has been succesfully obtained [14]. We also note that due to the higher spatial resolution of AFM-IR, some of the differences between TFTIR, GATR, and AFM-IR could represent feature to feature (fin-fin) variations in the chemical modification of the low-k dielectric. In this regard, we do note that while more than one fin was examined at each pitch, no attempt was made to map the variation in the chemical structure of the fins across the $1 \mathrm{~cm}^{2}$ array.

Despite the AFM-IR limitations, an overall consistent picture emerges for the chemical structure of the patterned low-k dielectric where the bulk of the fin (and portion of the bottom of 
the trench) is the same as that for the as-deposited blanket low-k dielectric film. However, the surfaces of the low-k fin and trench bottom are preferentially depleted of mono- $\mathrm{CH}_{3}$ by the $\mathrm{TiN}$ HM pre-clean and plasma etch (see Fig. 2c). In addition, the low-k fin sidewalls and trench bottom are coated with a thin hydrocarbon polymer residue layer (see Fig. 2c). As mentioned previously, this is supported by the T-FTIR and GATR-parallel spectra of the C-H stretch where additional $\mathrm{C}-\mathrm{H}_{2}$ stretching modes were observed in the patterned low-k that were not observed in the unpatterned/non-etched low-k dielectric. The presence of polymer residue in the trench bottom is further supported by the XSEM images presented in Fig. 1b where some polymer residue can be visualized and the GATR-parallel spectra where enhanced $\mathrm{C}-\mathrm{H}_{2}$ absorption from the polymer residue was observed at $630 \mathrm{~nm}$ pitch and the absorption from the trench bottom makes a more significant contribution to the spectrum (see supplemental material). Polymer residue on the fin sidewall is further supported by GATR-perpendicular spectra of the C-H stretch where enhanced $\mathrm{C}-\mathrm{H}_{2}$ absorption was observed relative to GATR-parallel (not shown).

To further explore the sensitivity of T-FTIR, GATR, and AFM-IR to modification of the chemical structure of the nano-patterned and nano-porous low-k dielectric, the previously examined samples were exposed to a series of different plasma ashes with increasing oxidation potential. These plasma ashes are commonly utilized post plasma etching to remove photoresist and any polymer residues that may have formed on the surfaces of patterned structures during plasma etching. From several prior studies [63-66], it has been well established that such plasma ashes typically selectively remove terminal methyl groups from the chemical structure / matrix of low-k dielectrics. The degree to which terminal methyl groups are removed depends on both the oxidation potential and length of the plasma ash exposure as well as the amount of interconnected nano-porosity present in the low-k dielectric. For extreme cases, a plasma ash can 
fully deplete a nano-porous low-k dielectric of terminal methyl groups and other organic components leaving behind an essentially porous $\mathrm{SiO}_{2}$ network.

Figure 7 presents the T-FTIR spectra collected from the previously investigated $180 \mathrm{~nm}$ pitch low-k fin structures exposed to a variety of plasma ash cleans with different oxidation potentials. Relative to the no ash spectrum, all T-FTIR spectra from the samples exposed to a plasma ash exhibited reduced absorbance for the $\mathrm{Si}_{-} \mathrm{CH}_{3}$ deformation band as expected [65]. The loss of $\mathrm{Si}_{-} \mathrm{CH}_{3}$ absorbance also clearly corresponded with the oxidation potential of the plasma ash and increased in the following order $\mathrm{He}-\mathrm{H}_{2}<\mathrm{Ar}-\mathrm{N}_{2}<\mathrm{He}-\mathrm{O}_{2}<\mathrm{N}_{2}-\mathrm{O}_{2}$. For the $\mathrm{N}_{2}-\mathrm{O}_{2}$ plasma ash T-FTIR spectrum, the $\mathrm{Si}_{-} \mathrm{CH}_{3}$ band actually completely disappeared and more closely resembled that for pure $\mathrm{SiO}_{2}$ [60]. As shown in Fig. 7b, the loss in absorbance for the $\mathrm{Si}^{-\mathrm{CH}_{3}}$ band also corresponded with a decrease in absorbance for both the $\mathrm{C}-\mathrm{H}_{2}$ and $\mathrm{C}-\mathrm{H}_{3}$ stretching bands. This indicates that abstraction of terminal methyl groups from the low-k dielectric coincides with removal of the surface polymer residues. Similar to the $\mathrm{Si}-\mathrm{CH}_{3}$ band, the C-H absorption band was essentially absent after the $\mathrm{N}_{2}-\mathrm{O}_{2}$ plasma ash (see Fig. 7b(iii)). Although not shown, identical effects were observed for the 270 and $630 \mathrm{~nm}$ pitch structures.

For GATR-parallel spectra from the same $180 \mathrm{~nm}$ pitch plasma clean samples (see Fig. 7c), the exact same trend in $\mathrm{Si}_{-} \mathrm{CH}_{3}$ loss with increasing plasma ash oxidation potential was also observed. Interestingly, the $\mathrm{Si}-\left(\mathrm{CH}_{3}\right)_{2}$ band at $1265 \mathrm{~cm}^{-1}$ decreased in intensity more quickly relative to the $1275 \mathrm{~cm}^{-1} \mathrm{Si}-\mathrm{CH}_{3}$ band in GATR-parallel as the oxidation potential of the plasma ash was increased. This may be due to both the top surface of the low-k fin being enriched in Si$\left(\mathrm{CH}_{3}\right)_{2}$ groups and the plasma ashes removing organic groups from the fin via a diffusion controlled process that starts at the surface and moves into the bulk of the nano-porous low-k dielectric [66]. Such a process would leave a $\mathrm{SiO}_{2}$ like surface or "crust" layer capping the low-k 
fin structure (see Fig. 7d). The presence of such crust or damage layers has been previously clearly demonstrated by Yonekura et al via exposing patterned and plasma ashed low-k structures to an $\mathrm{HF}$ wet chemical clean that selectively removes the $\mathrm{SiO}_{2}$ crust layer and results in a widening of the etched hanging trench [35]. As for T-FTIR, similar behavior was also observed using GATR-parallel for the 270 and $630 \mathrm{~nm}$ pitch structures and a corresponding decrease in $\mathrm{C}-\mathrm{H}$ absorbance with plasma ash oxidation potential was also observed. Similar results were also obtained using GATR-perpendicular as well (not shown).

Figure 8 shows AFM-IR spectra of the exact same structures investigated in Fig. 7 where increasing $\mathrm{Si}-\mathrm{CH}_{3}$ loss with plasma ash oxidation potential was again observed. Relative to $\mathrm{T}$ FTIR and GATR, however, the loss of $\mathrm{Si}_{-} \mathrm{CH}_{3}$ appears more accelerated in the AFM-IR spectra with the $\mathrm{Si}-\mathrm{CH}_{3}$ band being completely absent for both the $\mathrm{He}-\mathrm{O}_{2}$ and $\mathrm{N}_{2}-\mathrm{O}_{2}$ spectra and barely detectable even for the Ar- $\mathrm{N}_{2}$ plasma ash. This is attributed to the enhanced surface sensitivity for AFM-IR relative to T-FTIR and GATR and is consistent with the model that the $\mathrm{Si}^{-\mathrm{CH}_{3}}$ depletion by the plasma ash starts at the surface and progresses into the bulk of the low-k fin. For T-FTIR and GATR, some Si-CH3 absorbance is still detected for the $\mathrm{Ar}-\mathrm{N}_{2}$ and $\mathrm{He}-\mathrm{O}_{2}$ plasma ashes due to probing the whole low-k fin. However, AFM-IR of the same structures does not detect the $\mathrm{Si}-\mathrm{CH}_{3}$ due to either primarily probing just the organic depleted surface crust of the fin or due to the concentration of $\mathrm{Si}_{-} \mathrm{CH}_{3}$ groups dropping below the AFM-IR detection level.

Aside from the similarities and differences observed for the $\mathrm{Si}_{-} \mathrm{CH}_{3}$ deformation band by T-FTIR, GATR, and AFM-IR for the plasma ashed samples, additional similariites and differences were also observed for the Si-O stretch. Specifically, peak absorbance for the Si-O network stretch at $1050-1070 \mathrm{~cm}^{-1}$ was observed to increase in wavenumber as the oxidation potential of the plasma ash was increased and $\mathrm{Si}-\mathrm{CH}_{3}$ groups were removed from the dielectric. 
This is fully consistent with the low-k dielectric becoming more $\mathrm{SiO}_{2}$ like as the terminal organic groups were removed from the matrix by the plasma ash. For all three techniques, the Si-O "cage" stretching mode at $\sim 1150 \mathrm{~cm}^{-1}$ (Ref. 42) was similarly observed to decrease in absorbance relative to the main Si-O network stretching mode at $\sim 1050 \mathrm{~cm}^{-1}$ as the plasma ash oxidation potential increased and terminal organic groups were increasingly removed. More subtle differences in the Si-O lineshape and network/cage ratio exist in the spectra collected by the three different techniques that are likely related to the same subtleties previously identified and discussed for the $\mathrm{Si}-\mathrm{CH}_{3}$ band. In general, the broad trends present for both the $\mathrm{Si}-\mathrm{O}$ and $\mathrm{Si}-$ $\mathrm{CH}_{3}$ bands were identified by each technique.

From the above discussion, an overall consistent picture emerges for the plasma ash cleaned nano-patterned low-k dielectric samples based on the combined T-FTIR, GATR, and AFM-IR analysis. Specifically, terminal methyl groups and polymer residues are increasingly removed from the surfaces of both the low-k fin and hanging trench bottom as the plasma ash oxidation potential is increased. The extent of polymer residue removal and depth of the methyl abstraction from the low-k dielectric depends on both the oxidation strength of the plasma ash and the diffusion distance of the oxidizing species. For the highest oxidizing plasma clean investigated $\left(\mathrm{N}_{2}-\mathrm{O}_{2}\right)$, the polymer residue was completely removed and all the organic components were abstracted from the low-k dielectric resulting in essentially porous $\mathrm{SiO}_{2}$. For plasma cleans with intermediate oxidizing strength, the polymer residues were partially removed and a $\mathrm{SiO}_{2}$ like crust or "plasma damage" layer completely denuded of terminal organic groups was produced while an unpreturbed core in the low-k fin and bottom of the hanging trench was retained with terminal methyl concentrations similar to those in the as deposited low-k film (see Fig. 7d). 
Due to the high spatial resolution of AFM-IR, the schematic models for the chemical modification of the patterned low-k dielectric by the TiN HM pre-clean, plasma etch, and plasma ash presented in Figure $2 \mathrm{c}$ and $7 \mathrm{~d}$ could be potentially confirmed by examining the structures in cross section (i.e. cleaving structures and positioning AFM tip directly on fin and trench bottom cross section). Due to the effectively infinite thickness of the fin and trench bottom in cross section, this should overcome some of the thickness challenges and sensitivity issues experienced in this study and allow the chemical structure of the nano-porous low-k dielectric within the fin and trench bottom to be mapped directly. Unfortunately, the authors have currently had limited success with such approaches due to probe thermal drift issues and challenges associated with producing suitably flat cross sectioned samples without inducing additional damage to the low-k dielectric. However, such PTIR cross section measurements will be the subject of continued future investigation and research.

\section{Conclusion}

The combined results presented in this study establish a strong direct link between micron scale FTIR and GATR and nano scale AFM-IR spectra of nanometer scale features. The results clearly demonstrate that the same general trends and relations in the chemical structure of nano-scale objects are observed by all three techniques and for chemically uniform structures virtually identical results should be obtained. However, in the presence of chemical structure non-uniformity, each technique can yield slightly different results due to differences in both the geometry and physics of the technique that lead to different volumes of the test object being probed. The degree of disagreement between techniques will depend on the orientation and 
spatial magnitude of the chemical structure gradient with respect to the sensitivity and probe volume of the individual technique.

This study also strongly establishes AFM-IR as a technique capable of detecting and discriminating differences and changes in the chemical structure of nano-scale objects that might otherwise go undetected in micron-macro scale arrays of the same objects. This is a particularly important advantage for process monitoring and failure analysis in nano-electronic devices where fabrication of micron-macro scale arrays is generally incompatible with product layout and failure analysis of a single faulty nanoscale device in a sea of similar operative devices may be required.

\section{Acknowledgments}

The authors would like to acknowledge the support and encouragement of Drs. Bruce Tufts, Jose Mais, and David Shykind of Intel Corporation. We would also like to acknowledge insightful discussions and input from Dr. Milan Milosevic of MeV Technolgies concerning optical coupling in T-FTIR and GATR measurements. Anasys Instruments would like to acknowledge SBIR funding from the National Science Foundation (grants 1126871 and IIP1152308). 


\section{References}

[1] Kuhn, K. Microelectron. Eng. 2011, 88, 1044-1049.

[2] Gupta, S.; Moroz, V.; Smith, L.; Lu, Q.; Saraswat, K. IEEE Trans. Electron Devices 2014, $61,1222-1230$.

[3] Lin, B. Microelectron. Eng. 2015, 143, 91-101.

[4] King, S.; Simka, H.; Herr, D.; Akinaga, H.; Garner, M. APL Mater. 2013, 1, 40701-8.

[5] Aspnes, D. J. Vac. Sci. Technol. A 2013, 31, 58502-14.

[6] Diebold, A. J. Vac. Sci. Technol. A 2013, 31, 50804-10 (2013).

[7] Pennycook, S. MRS Bull. 2015, 40, 71-78.

[8] Gross, L. Nat. Chem. 2011, 3, 273-278.

[9] Stan, G.; King, S.; Cook, R. Nanotechnology 2012, 23, 215703-9.

[10] Jarausch, K.; Thomas, P.; Leonard, D.; Twesten, R.; Booth, C. Ultramicroscopy 2009, 108, 326-337.

[11] Tolstoy, V.; Chernyshova, I.; Skryshevsky, V. Handbook of Infrared Spectroscopy of Ultrathin Films. (John Wiley \& Sons, New York, 2012).

[12] Milosevic, M. Internal Reflection and ATR Spectroscopy (John Wiley \& Sons, New York, 2012).

[13] Dazzi, A; Glotin, F.; Carminati, R. J. Appl. Phys. 2010, 107, 124519-7.

[14] Lahiri, B.; Holland, G.; Centrone, A. Small 2013, 9, 439 - 445.

[15] Katzenmeyer, A; Aksyuk, V; Centrone, A. Anal. Chem. 2013, 85, 1972-1979.

[16] Katzenmeyer, A; Holland, G.; Kjoller, K.; Centrone, A. Anal. Chem. 2015, 87, 3154-3159. 
[17] Kulik, A.; Ruggeri, F.; Gruszecki, W.; Dietler, G. Microscopy and Analysis 2014, 28 (4), 11 $-15$.

[18] Dazzi, A.; Prater, C.; Hu, Q.; Chase, B.; Rabolt, J.; Marcott, C. Appl. Spectrosc. 2012, 66, 1365-1384.

[19] Hammiche, A.; Pollock, H.; Reading, M.; Claybourn, M.; Turner, P.; Jewkes, K. Appl. Spectrosc. 1999, 53, 810-815.

[20] Kjoller, K.; Felts, J.; Cook, D.; Prater, C.; King, W. Nanotechnology 2010, 21, 185705-6.

[21] Marcott, C.; Lo, M.; Kjoller, K.; Prater, C.; Noda, I. Appl. Spectrosc. 2011, 65, 1145-1150.

[22] Felts, J.; Kjoller, K.; Lo, M.; Prater, C.; King, W. ACS Nano 2012, 6, 8015-8021.

[23] Huth, F.; Govyadinov, A.; Amarie, S.; Nuansing, W.; Keilmann, F.; Hillenbrand, R. Nano Lett. 2012, 12, 3873-3978.

[24] Katzenmeyer, A.; Chae, J.; Kasica, R.; Holland, G.; Lahiri, B.; Centrone, A. Adv. Optical Mater. 2014, 2, 718-722.

[25] Felts, J.; Law, S.; Roberts, C.; Podolskiy, Wasserman, D.; King, W. Appl. Phys. Lett. 2013, $102,152110-5$.

[26] Mukherjee, T.; Berhe, S.; Goswami, A.; Chyan, O.; Singh, K.; Brown, I. ACS Appl. Mater. Interfaces 2015, 7, $5051-5055$.

[27] Maex, K.; Baklanov, M.; Shamiryan, D.; Iacopi, F.; Brongersma, S.; Yanovitskaya, Z. J. Appl. Phys. 2003, 93, $8793-8841$.

[28] Volksen, W.; Miller, R.; Dubois, G. Chem. Rev. 2010, 110, 56 - 110.

[29] Grill, A.; Gates, S.; Ryan, T.; Nguyen, S.; Priyadarshini, D. Appl. Phys. Rev. 2014, 1, 011306-17.

[30] King, S. ECS J. Sol. State Science Technol. 2015, 4, N3029 - N3047. 
[31] Baklanov, M.; de Marneffe, J.; Shamiryan, D.; Urbanowicz, A.; Shi, H.; Rakhimova, T.; Huang, H.; Ho, P. J. Appl. Phys. 2013, 113, 041101-41.

[32] Yonekura, K.; Goto, K.; Matsuura, M.; Fujiwara, N.; Tsujimoto, K. Jpn. J. Appl. Phys. 2005, 44, $2976-2981$.

[33] Badam, R.; Mukherjee-Roy, M.; Shaoyu, W.; Naman, A. Jpn. J. Appl. Phys. 2004, 43, 7381 $-7385$.

[34] Guo, X.; Jakes, J.; Banna, S.; Nishi, Y.; Shohet, J. J. Appl. Phys. 2014, 116, 044103-9.

[35] Yonekura, K.; Sakamori, S.; Goto, K.; Matsuura, M.; Fujiwara, N.; Yoneda, M. J. Vac. Sci. Technol. B 2008, 22, 548 - 553.

[36] Padovani, A.; Riester, L.; Rhodes, L.; Allen, S.; Kohl, P. J. Electrochem. Soc. 2002, 149, F171 - F180.

[37] Stan, G.; Ciobanu, C.; Levin, I.; Yoo, H.; Myers, A.; Singh, K.; Jezewski, C.; Miner, B.; King, S. Nano Lett. 2015, 15, 3845-3850.

[38] Yang, C.; Ko, C.; OuYang, H.; Chen, K.; Peng, Y.; Liou, J.; Chou, C.; Tsai, H.; Lin, K.; Jeng, S.; Tao, H.; Cao, M. Solid State Phenomena 2012, 187, 253 - 256.

[39] Wang, G.; Ho, P.; Groothuis S. Micro. Rel. 2005, 45, 1079 - 1093.

[40] Borja, J.; Plawsky, J.; Lu, T.; Bakhru, H.; Gill, W. ECS J. Solid State Sci. Technol. 2014, 3, N59-N61.

[41] Chen, F.; Bravo, O.; Harmon, D.; Shinosky, M.; Aitken, J. Micro. Rel. 2008, 48, 1375 1383.

[42] Gates, S.; Neumayer, D.; Sherwood, M.; Grill, A.; Wang, X.; Sankarapandian, M. J. Appl. Phys. 2007, 101, 094103-8. 
[43] Bao, J.; Shi, H.; Liu, J.; Huang, H.; Ho, P.; Goodner, M.; Moinpour, M.; Kloster, G. J. Vac.

Sci. Technol. B 2008, 26, $219-226$.

[44] Takeda, K.; Miyawaki, Y.; Takashima, S.; Fukasawa, M.; Oshima, K.; Nagahata, K.;

Tatsumi, T.; Hori, M. J. Appl. Phys. 2011, 109, 033303-5.

[45] Shi, H.; Huang, H.; Bao, J.; Liu, J.; Ho, P.; Zhou, Y.; Pender, J.; Armacost, M.; Kyser, D. J. Vac. Sci. Technol. B 2012, 30, 011206-9.

[46] Bruce, R.; Engelmann, S.; Purushothaman, S.; Volksen, W.; Frot, T.; Magbitang, T.;

Dubois, G.; Darnon, M. J. Phys. D: Appl. Phys. 2013, 46, 265303-6.

[47] Cheng, Y.; Huang, J.; Chang, Y.; Leu, J. Thin Solid Films 2013, 544, 537 - 540.

[48] Lee, W.; Kim, H.; Park, W.; Kim, W.; Kim, D.; Kim, J.; Cheong, H.; Whang, K. J. Appl.

Phys. 2015, 117, 173302-6.

[49] Oszinda, T.; Beyer, V.; Schaller, M.; Fischer, D.; Bartsch, C. J. Vac. Sci. Technol. B 2009, $27,521-526$.

[50] Lam, J.; Huang, M.; Tan, H.; Mo, Z.; Mai, Z.; Wong, C.; Sun, H.; Shen, Z. J. Vac. Sci.

Technol. A 2011, 29, 051513-6.

[51] Mukherjee, T.; Rimal, S.; Koskey, S.; Chyan, O.; Singh, K.; Myers, A. ECS Solid State Lett. 2013, 2, N11-N14.

[52] Rimal, S.; Mukherjee, T.; Abdelghani, J.; Goswami, A.; Chyan, O.; Stillahn, J.; Chiba, Y.; Maekawa, K. ECS Solid State Lett. 2014, 3, N1-N4.

[53] Lo, M.; Dazzi, A.; Marcott, C.; Dillon, E.; Hu, Q.; Kjoller, K.; Prater, C.; King, S. ECS J. Solid State Sci. and Tech. 2016, 5, P3018.

[54] Phung, T.; Johnson, D.; Antonelli, A. J. Appl. Phys. 2006, 100, 064317-6.

[55] Grill, A. J. Appl. Phys. 2003, 93, 1785 - 1790. 
[56] Katzenmeyer, M.; Canivet, J.; Holland, G.; Farrusseng, D.; Centrone, A. Agnew. Chem. 2014, 126, $2896-2900$.

[57] King, S.; Milosevic, M. J. Appl. Phys. 2012, 111, 073109-9.

[58] Milosevic, M.; King, S. J. Appl. Phys. 2012, 112, 093514-7.

[59] Milosevic, M.; King, S. ECS J. Solid State Sci. Technol. 2015, 4, N3146 - N3152.

[60] Pomorski, T.; Bittel, B.; Lenahan, P.; Mays, E.; Ege, C.; Bielefeld, J.; Michalak, D.; King, S. J. Appl. Phys. 2014, 115, 234508-20.

[61] Bailey, S.; Mays, E.; Michalak, D.; Chebiam, R.; King, S.; Sooryakumar, R. J. Phys. D: Appl. Phys. 2013, 45, 045308-7.

[62] King, S.; French, M.; Jaehnig, M.; Kuhn, M.; French. B. Appl. Phys. Lett. 2011, 99, 202903-

3.

[63] Shoeb, J.; Wang, M.; Kushner, M. J. Vac. Sci. Technol. A 2012, 30, 041303-15.

[64] Yamamoto, H.; Asano, K.; Ishikawa, K.; Sekine, M.; Hisataka, H.; Sakai, I.; Ohiwa, T.;

Takeda, K.; Kondo, H.; Hori, M. J. Appl. Phys. 2011, 110, 123301-8.

[65] Olawumi, T.; Levrau, E..; Krishtab, M.; Detavernier, C,; Bartha J.; Xu, K.; Lazzarino, F.;

Baklanov, M. ECS J. Solid State Sci. Technol. 2015, 4, N3048 - N3057.

[66] Goldman, M.; Graves, D.; Antonelli, A.; Behera, S.; Kelber, J. J. Appl. Phys. 2009, 106, 013311-7. 


\section{Figure Captions}

Fig. 1. (a) Top down schematic of the patterned nano-porous low-k dielectric, (b) top down SEM image of the patterned low-k dielectric (c) Schematic cross section of patterned low-k dielectric hanging trench structures. The green layer in between the Si (001) substrate and the patterned low-k dielectric is an $8 \mathrm{~nm}$ dense a-SiOC:H adhesion / etch stopping layer. (d) XSEM image of actual low-k hanging trench structures investigated.

Fig. 2. Transmission FTIR spectra of (a) the Si-O stretch $\left(1000-1250 \mathrm{~cm}^{-1}\right)$ and $\mathrm{Si}_{-} \mathrm{CH}_{3}$ deformation band (1275 $\left.\mathrm{cm}^{-1}\right)$, and (b) the C-H (2800-3000 $\left.\mathrm{cm}^{-1}\right)$ and O-H (3200-3600 $\left.\mathrm{cm}^{-1}\right)$ stretches from (i) unpatterned and patterned nano-porous low-k dielectric with pitch of (ii) 180 nm, (iii) $270 \mathrm{~nm}$, and (iv) $630 \mathrm{~nm}$. To more clearly illustrate and compare differences, the Si-O stretching mode at $1050 \mathrm{~cm}^{-1}$ has been normalized in each spectrum to have the same absorbance. (c) Schematic cross section of the nano-porous low-k dielectric fin and trench illustrating variations in chemical composition and the presence of residue layers after plasma etching. Blue indicates pristine low-k dielectric material, green indicates low-k dielectric damaged by the hardmask deposition and removal process, yellow and red indicate $\mathrm{CH}_{3}$ depleted low-k dielectric and surface residues, respectively, induced by the plasma etch process.

Fig. 3. $\mathrm{Si}-\mathrm{CH}_{3} / \mathrm{Si}-\mathrm{O}$ ratio from T-FTIR, GATR-parallel, GATR-perpendicular and PTIR spectra of the patterned nano-porous low-k dielectric as a function of pitch. For T-FTIR and GATR, the error bars represent the maximum and minimum values determined from a single spectrum accounting for variations in baseline and peak height resulting from the $\mathrm{S} / \mathrm{N}$ ratio of each 
spectrum. For PTIR, the error bars were similarly determined from spectra acquired from three randomly selected fins at each pitch. The wider PTIR error bars are attributed to both the reduced S/N for PTIR relative to T-FTIR and GATR as well as plasma etch induced fin to fin composition variability.

Fig. 4. Cross section comparison of sample-IR source-detector geometry for (a) T-FTIR, (b) GATR with the low-k fins oriented parallel to the IR source, (c) GATR with the low-k fins oriented perpendicular to the IR source, and (d) PTIR.

Fig. 5. AFM-IR spectra of the $\mathrm{Si}-\mathrm{O}$ stretch and $\mathrm{Si}-\mathrm{CH}_{3}$ deformation bands for the patterned nano-porous low-k dielectric with pitch of (a) $180 \mathrm{~nm}$, (b) $270 \mathrm{~nm}$, and (c) $630 \mathrm{~nm}$. To more clearly illustrate and compare differences, the $\mathrm{Si}-\mathrm{O}$ stretching mode at $1050 \mathrm{~cm}^{-1}$ has been normalized in each spectrum to have the same absorbance.

Fig. 6. IR spectra of the $\mathrm{Si}-\mathrm{O}$ stretch and $\mathrm{Si}-\mathrm{CH}_{3}$ deformation bands for the patterned nanoporous low-k dielectric at $180 \mathrm{~nm}$ pitch obtained via (a) T-FTIR, (b) GATR with fins oriented parallel to the IR source, (c) GATR with fins oriented perpendicular to the IR source, and (d) AFM-IR. To more clearly illustrate and compare differences, the Si-O stretching mode at 1050 $\mathrm{cm}^{-1}$ has been normalized in each spectrum to have the same absorbance.

Fig. 7. Transmission FTIR spectra of (a) the Si-O stretch and $\mathrm{Si}-\mathrm{CH}_{3}$ deformation bands, (b) Transmission FTIR spectra of the C-H and O-H stretching bands, and (c) GATR-parallel spectra of the $\mathrm{Si}-\mathrm{O}$ stretch and $\mathrm{Si}-\mathrm{CH}_{3}$ deformation bands for the $180 \mathrm{~nm}$ pitch patterned nano-porous low-k dielectric exposed to the following post patterning ashes (i) none, (ii) $\mathrm{He}-\mathrm{H}_{2}$, (iii) $\mathrm{Ar}-\mathrm{N}_{2}$, 
(iv) $\mathrm{He}-\mathrm{O}_{2}$, and (v) $\mathrm{N}_{2}-\mathrm{O}_{2}$. To more clearly illustrate and compare differences, the Si-O stretching mode at $1050 \mathrm{~cm}^{-1}$ has been normalized in each spectrum to have the same absorbance. (d) Schematic cross section of the nano-porous low-k dielectric fin and trench illustrating variations in chemical composition after plasma ashing/oxidation treatments.

Fig. 8. AFM-IR spectra of the $\mathrm{Si}-\mathrm{O}$ stretch and $\mathrm{Si}_{-} \mathrm{CH}_{3}$ deformation bands for the $180 \mathrm{~nm}$ pitch patterned nano-porous low-k dielectric exposed to the following post patterning ashes (a) none, (b) $\mathrm{He}-\mathrm{H}_{2}$, (c) $\mathrm{Ar}-\mathrm{N}_{2}$, (d) $\mathrm{He}-\mathrm{O}_{2}$, and (e) $\mathrm{N}_{2}-\mathrm{O}_{2}$. To more clearly illustrate and compare differences, the Si-O stretching mode at $1050 \mathrm{~cm}^{-1}$ has been normalized in each spectrum to have the same absorbance. 

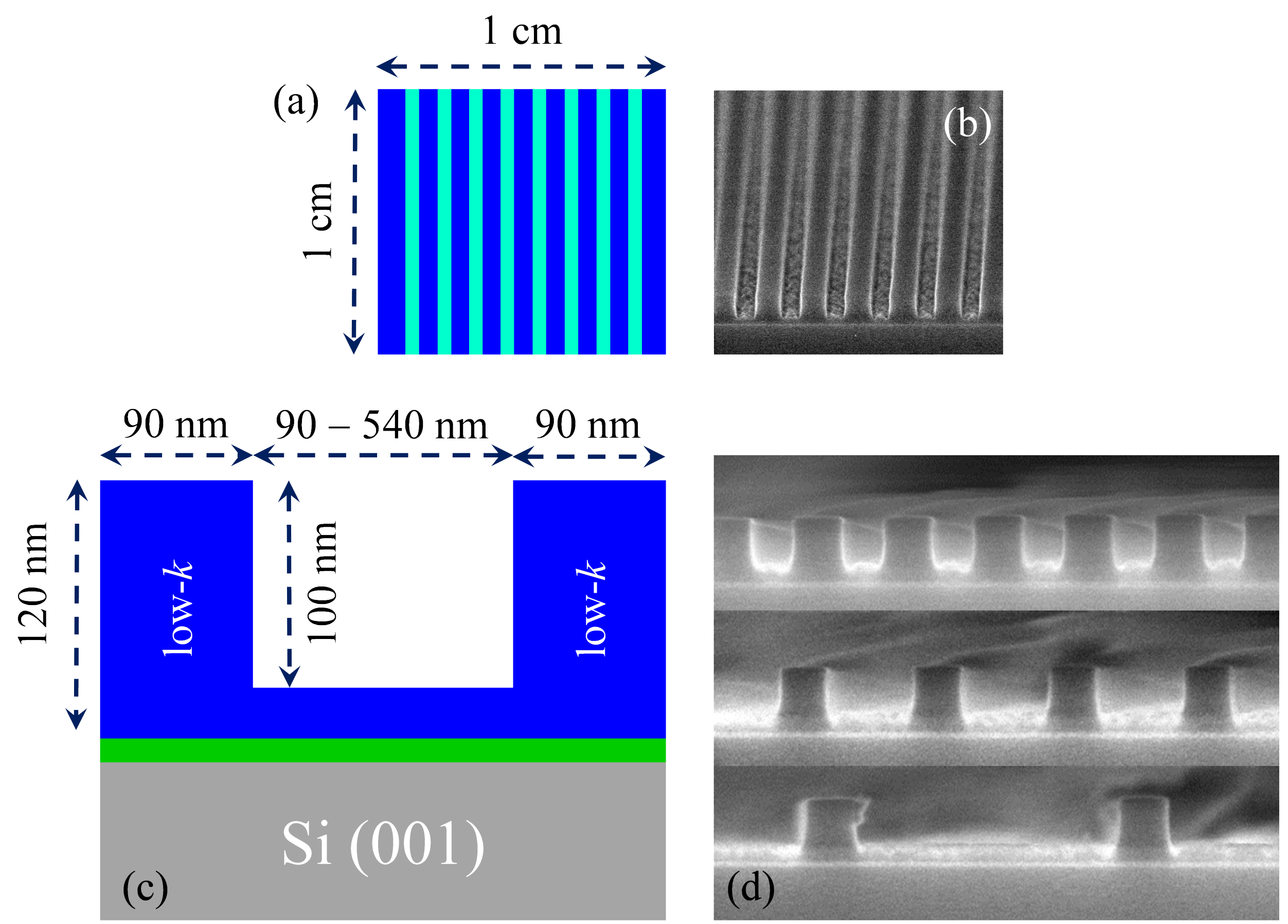


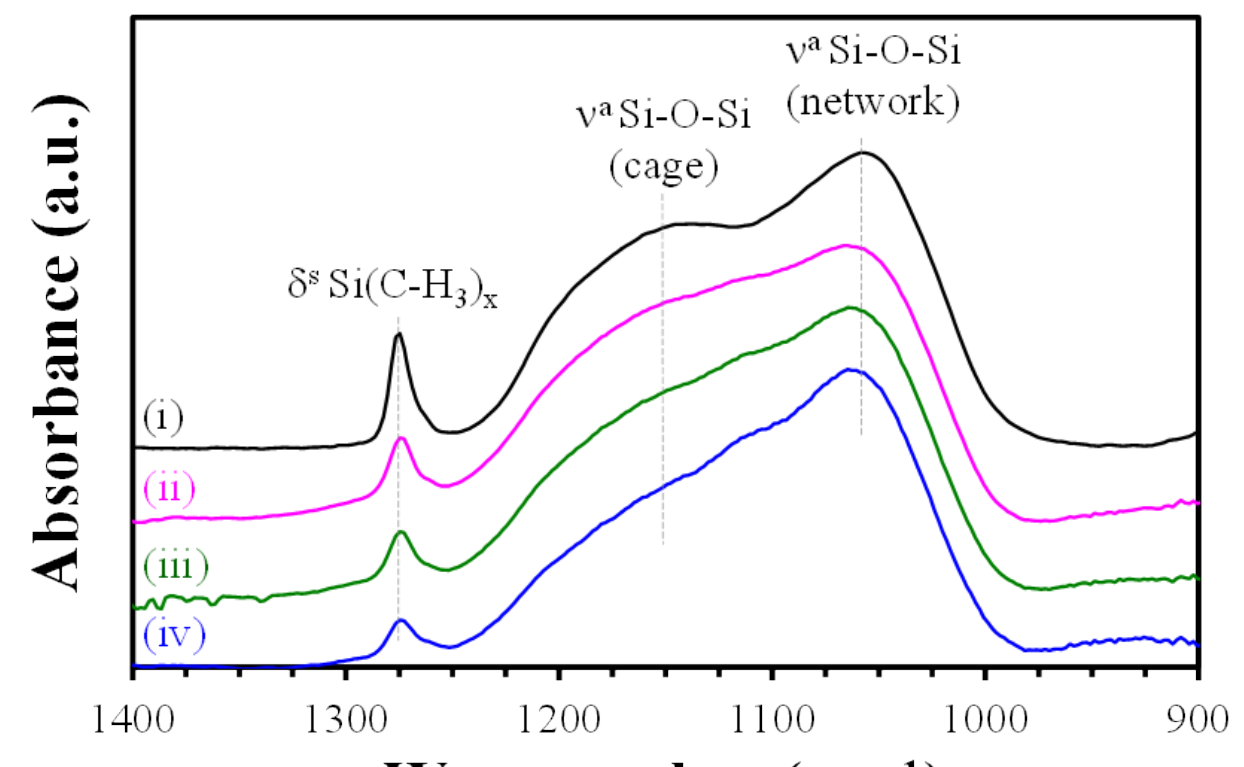

HM Damaged
top fin surface

Etched low-k trench bottom \& plasma etch residue

(a) Wavenumber $\left(\mathrm{cm}^{-1}\right)$

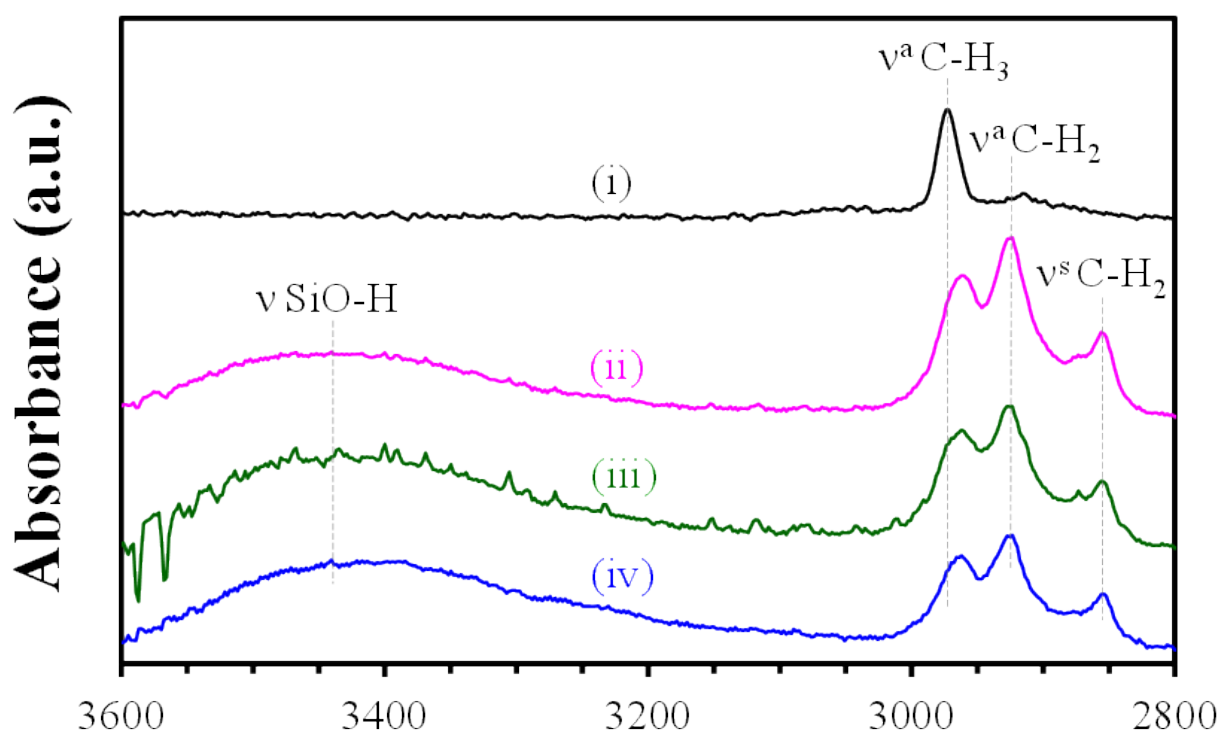

(c)

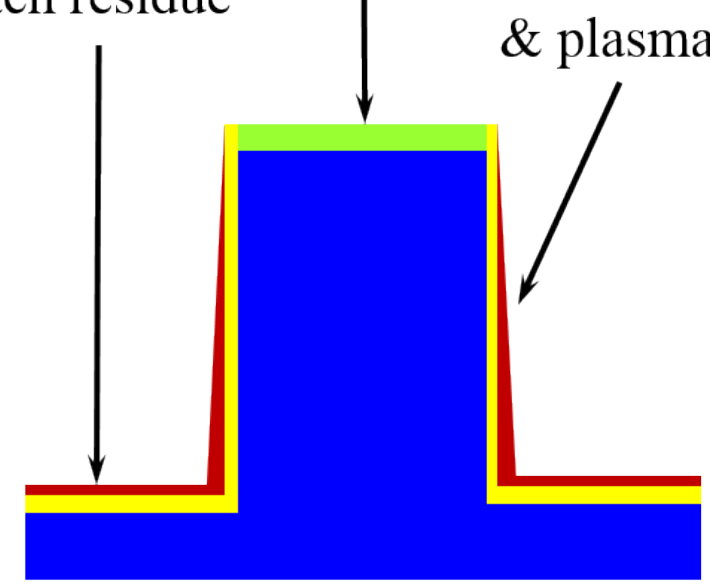

(b) Wavenumber $\left(\mathrm{cm}^{-1}\right)$ 


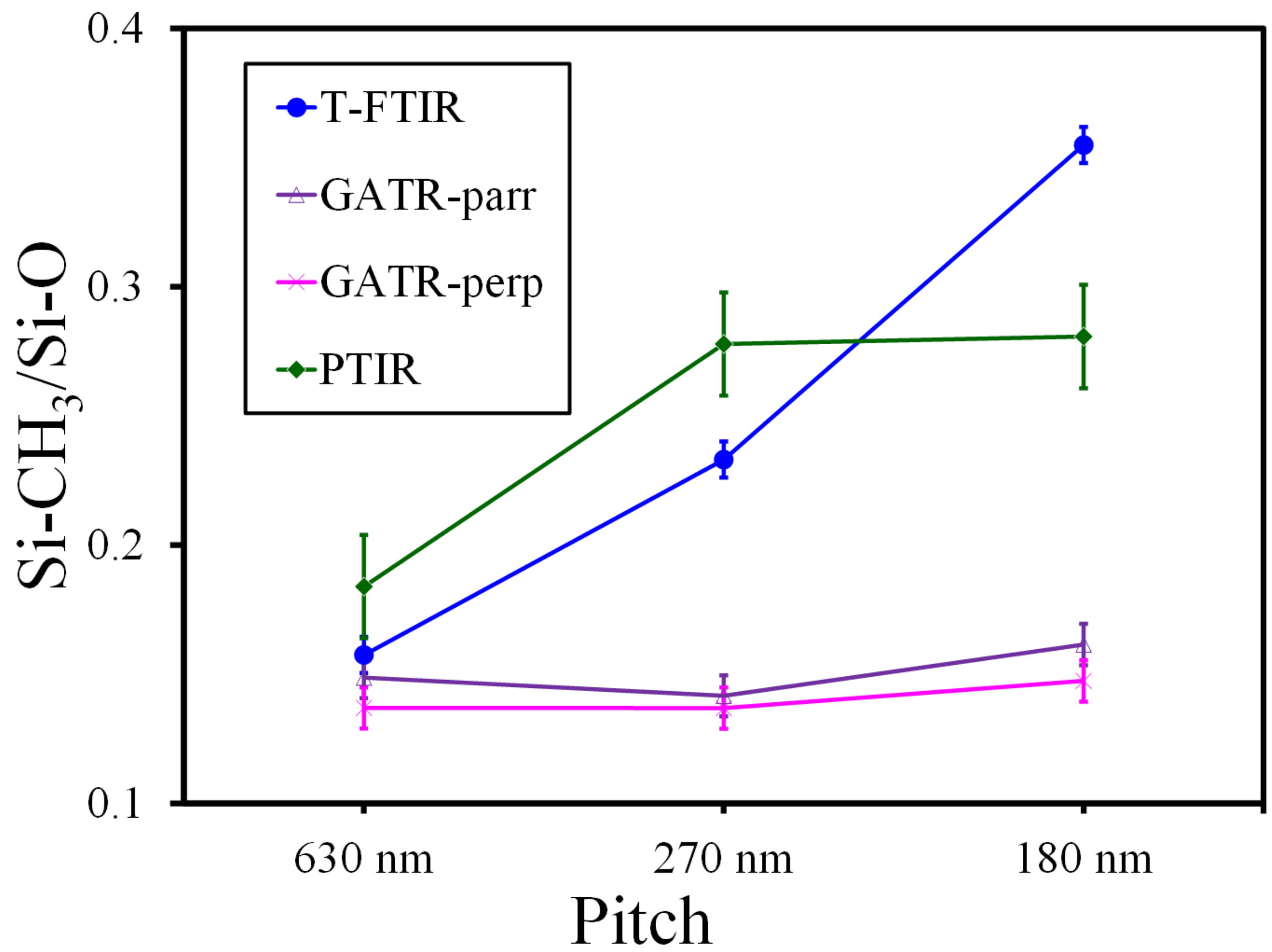




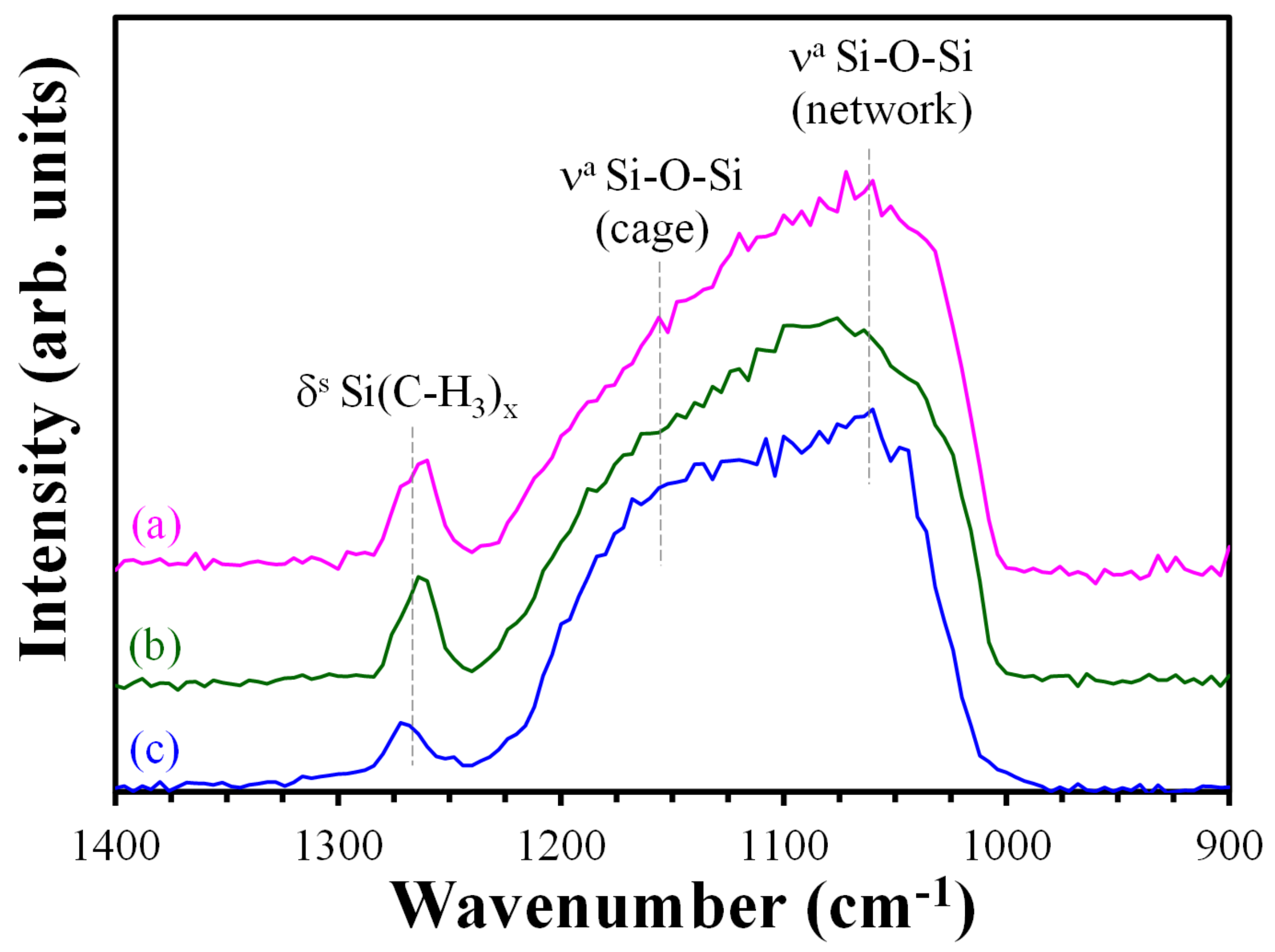




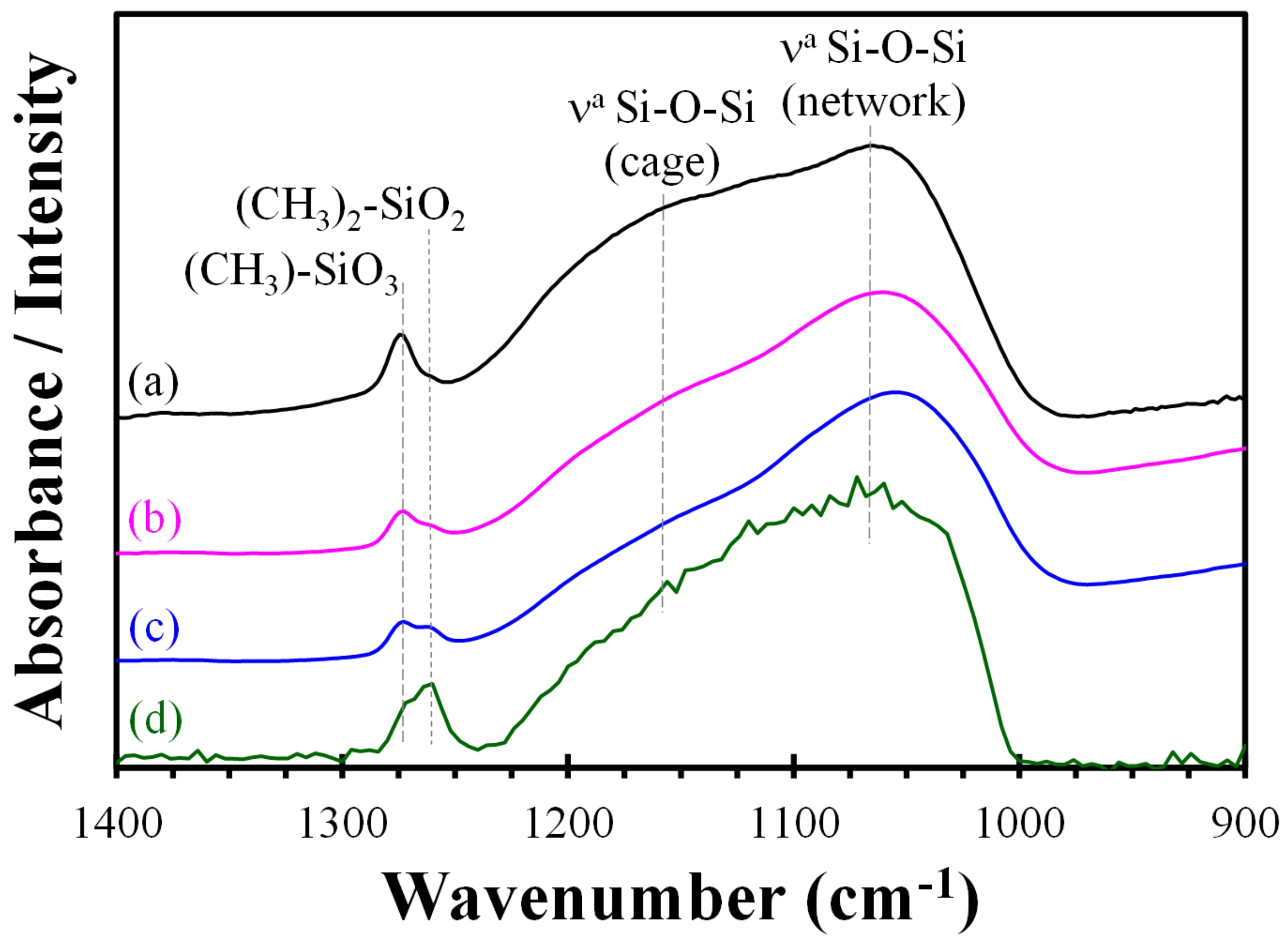




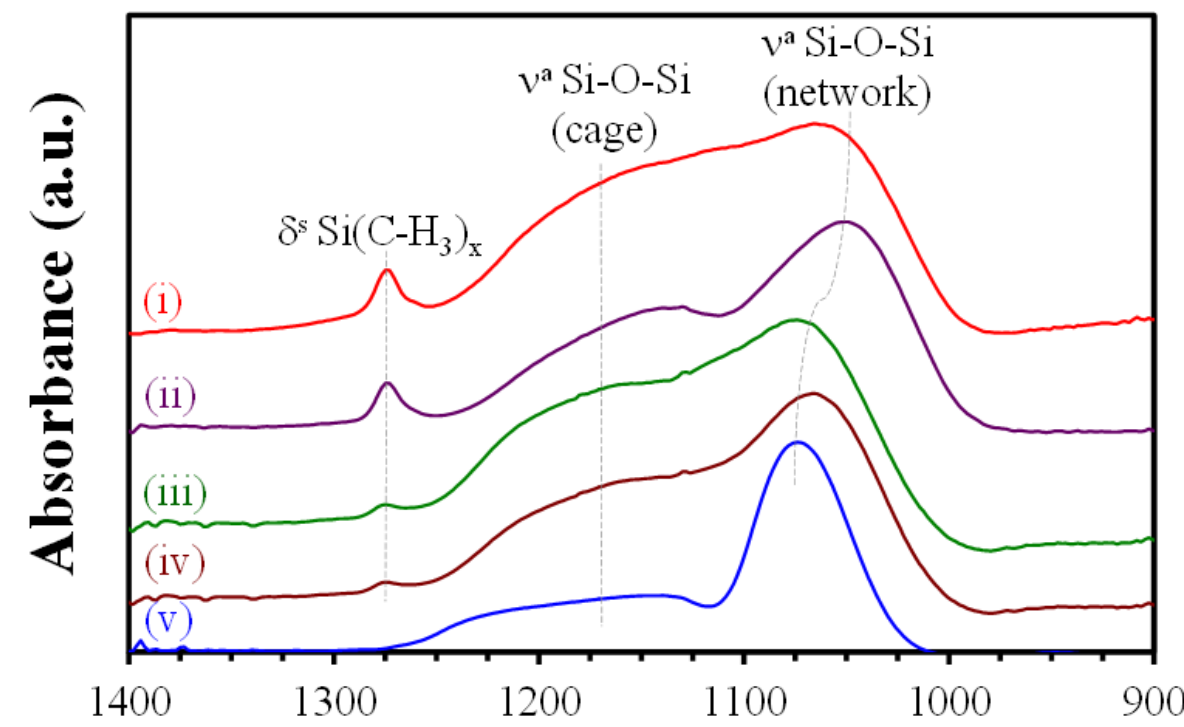

(a)

Wavenumber $\left(\mathrm{cm}^{-1}\right)$

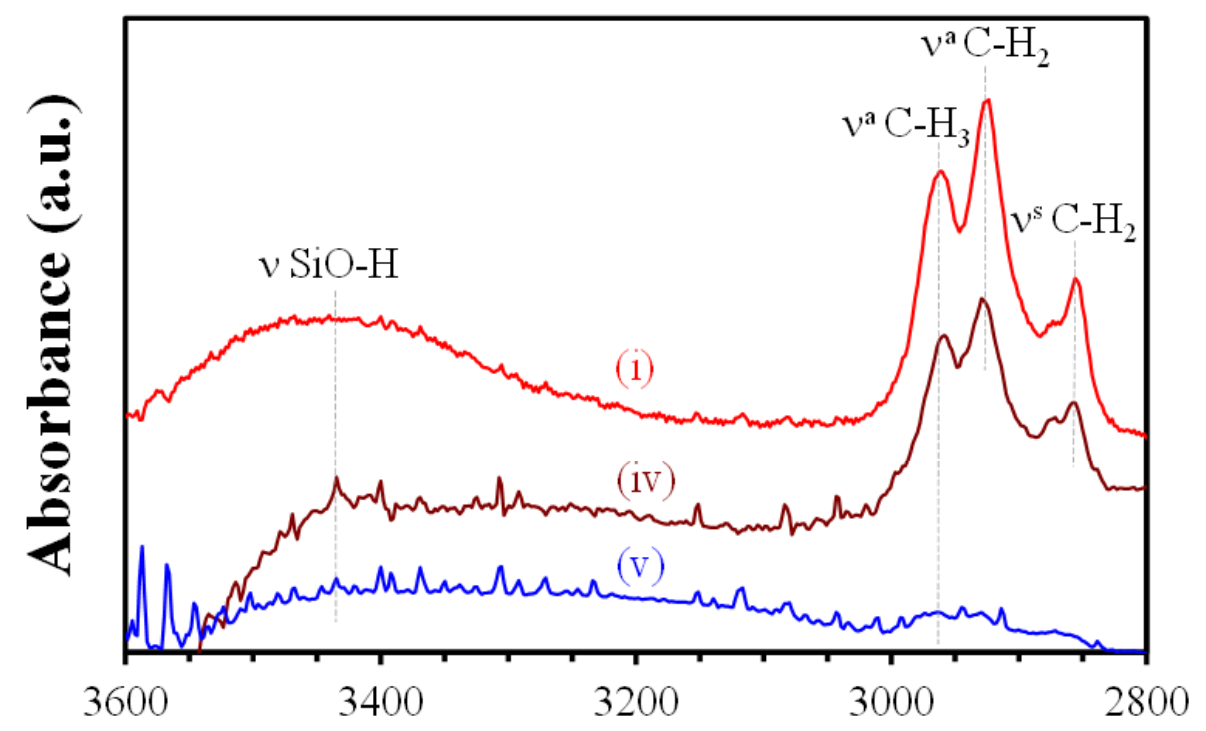

(b) Wavenumber $\left(\mathrm{cm}^{-1}\right)$

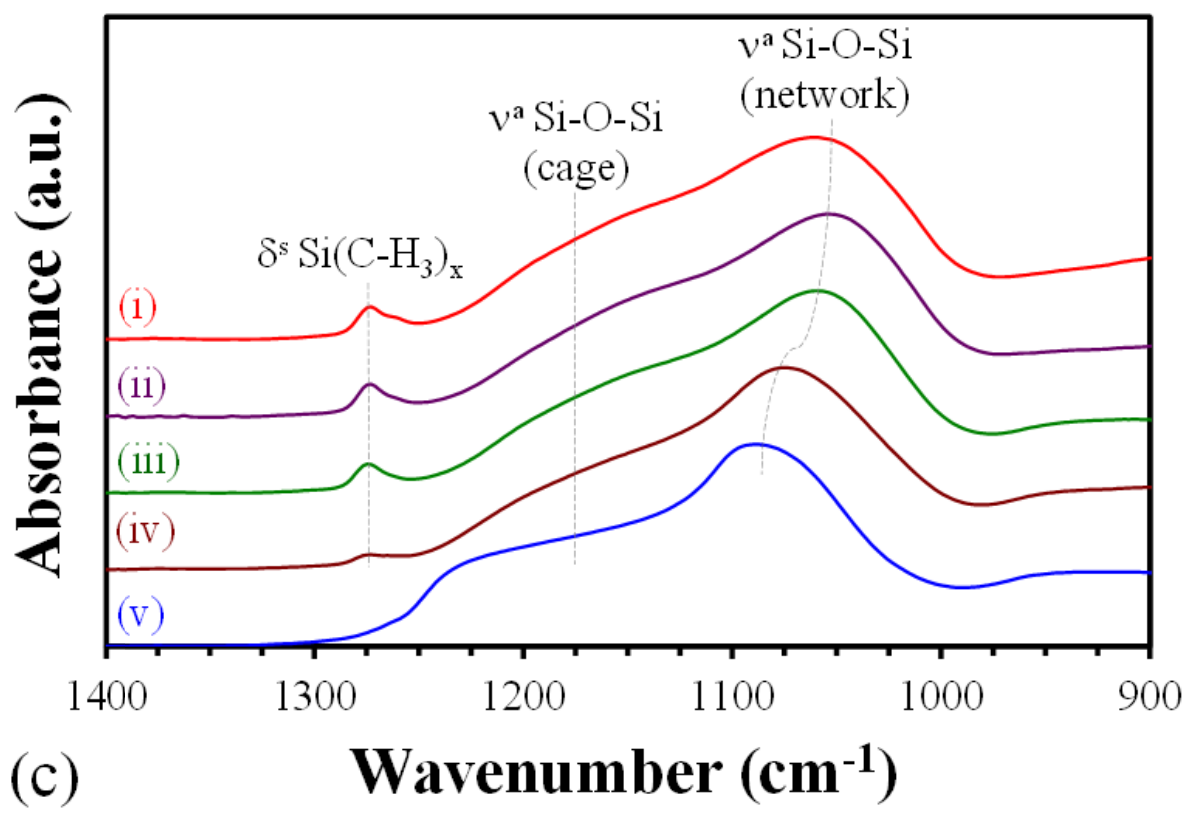

(d) trench surfaces

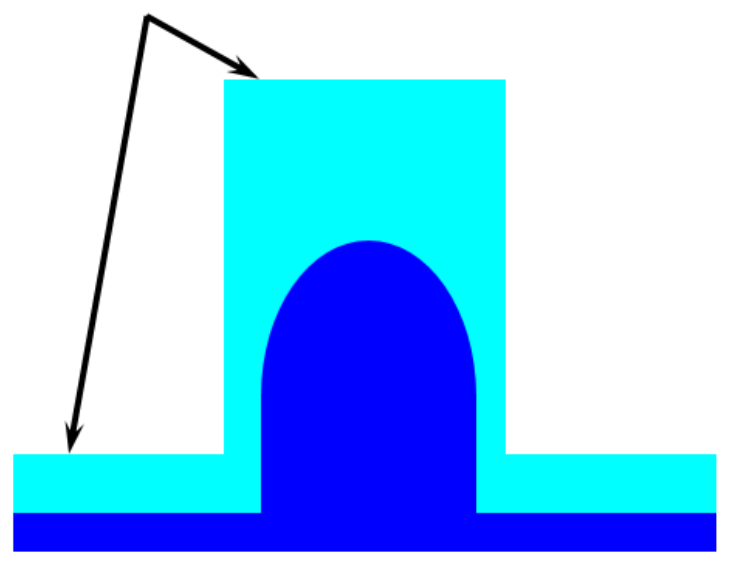




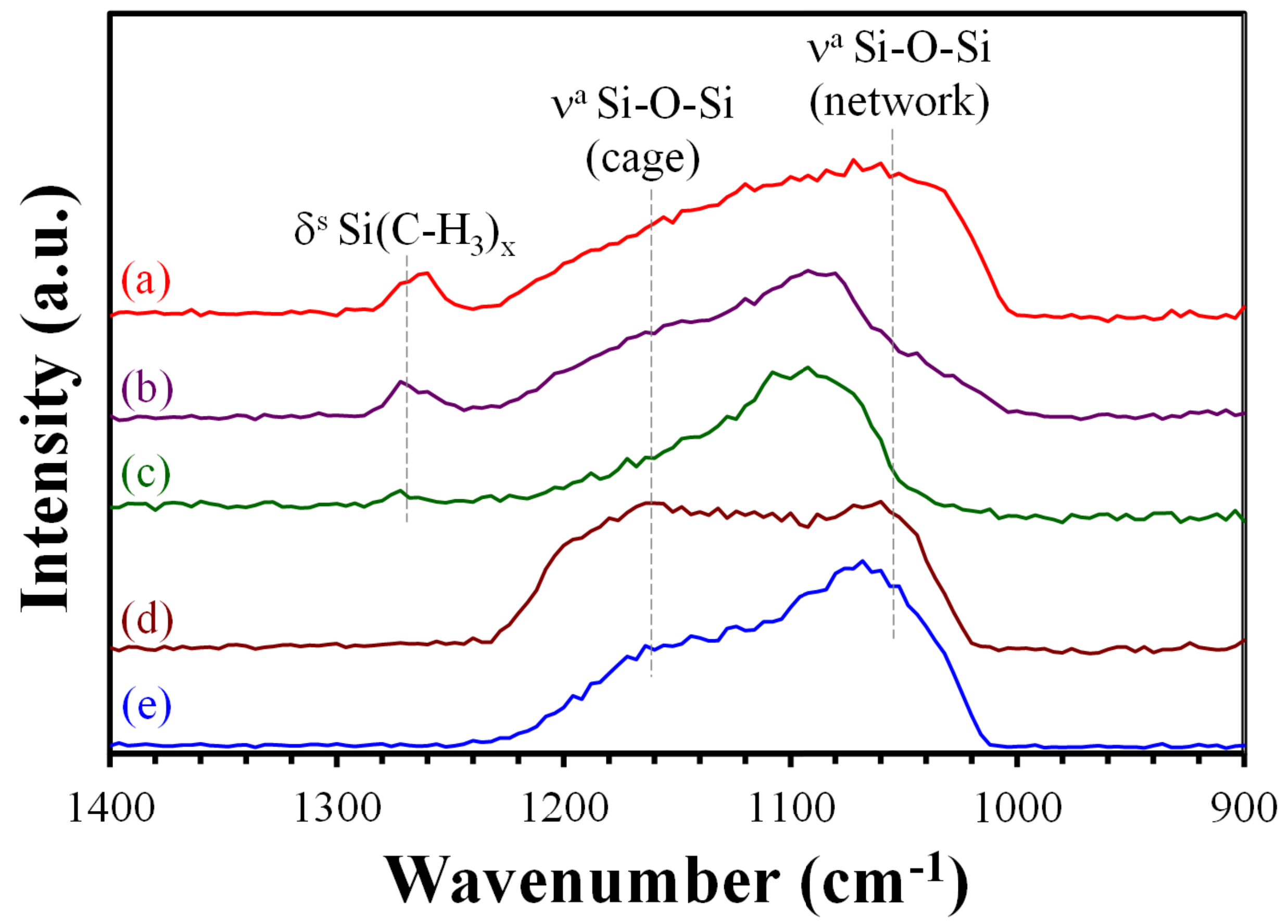

